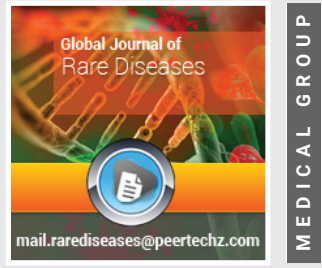

\title{
Cutis marmorata telangiectasia congenita-a needle in the neonatal dermatology
}

\section{haystack?}

\author{
Hassan Shakeel ${ }^{1-4 \star}$ and Ather Ahmed ${ }^{2}$ \\ 'Department of Paediatrcs, University of Cambridge, Addenbrooke's Hospital, Hill's Road, CB2 OQQ, UK \\ ${ }^{2}$ Department of Paediatrics and Neonatology, Lister Hospital, Stevenage, SG1 4AB, UK \\ ${ }^{3}$ Wellcome Trust Sanger Institute, Hinxton, Cambridgeshire, CB10 1SA, UK \\ ${ }^{4}$ National Institute for Health Research, 79 Whitehall, London, SW1A 2NS, UK
}

\begin{abstract}
Cutis Marmorata Telangiectasia Congenita (CMTC, also known as van Lohuizen syndrome) is a rare disorder characterised by dilatation of the cutaneous vasculature. This results in a blue-purple 'marbled' appearance of the skin due to telangiectasia, phlebectasia and persistent cutis marmorata. It is often mistaken for benign cutis marmorata and is therefore likely underdiagnosed. CMTC can occur in connection with other dysmorphic findings in several syndromes (e.g. Adams-Olivers) or in isolation. We review the evidence surrounding the epidemiology, pathophysiology and management of isolated CMTC, and contextualize it with a case.
\end{abstract}

\section{Case report}

\section{Epidemiology}

CMTC is believed to be very rare, with less than 1 in 1 million individuals affected, and approximately 300 cases have been described to date [1-3], after its first description [4]. There appears to be no racial bias in the development of CMTC and most cases are diagnosed during the neonatal period, although sometimes there is a significant lag time to diagnosis due to a degree of diagnostic uncertainty. Isolated CMTC is essentially a diagnosis of exclusion. No significant gender bias has thus far been demonstrated, though some do believe there to be a female preponderance [5], yet more data is required to investigate these claims.

\section{Pathophysiology}

The pathophysiology of isolated CMTC remains uncertain. However, there are notions that its pathogenesis is associated with fetal ascites and elevated maternal bHCG [6]. There has also been a gene mutation of ARL6IP6 described in a single consanguineous Arabian pedigree [7]. A genetic explanation has also been posed in favour of Happle lethal gene hypothesis [8], suggesting that genetic mosaicism is likely the cause of the random patches of CMTC often found in affected children.

Isolated CMTC can be associated with other pathologic features. These commonly include congenital glaucoma, syndactyly, renal hypoplasia, body asymmetry, cutaneous atrophy and neurological abnormalities.

Non-isolated CMTC is a recognised feature in a number of syndromes (Figure 3), yet the pathophysiological mechanisms by which it occurs as a feature of these is poorly understood.

\section{Prognosis and management}

The prognosis of isolated CMTC in generally good; with $46 \%$ of patients having spontaneous improvement of the lesion(s) by 3 years of age. There is also thought to be no effect on mortality, nor on life expectancy. The serpiginous skin lesions can occasionally ulcerate resulting in haemorrhage ${ }^{3}$, but with good supportive care this problem can be effectively prevented. 
However, when CMTC is found to be a feature of a syndrome, the prognosis is often worse in terms of both morbidity and mortality.

The management of CMTC initially involves characterisation of further dysmorphism/congenital anomalies (to determine whether it is syndromic), which is usually done by radiological imaging. Ocular investigation is also required as it is associated with congenital glaucoma, suprachoroidal haemorrhage and retinal detachment. CMTC itself is usually treated passively, but its associated anomalies may require medical or surgical intervention. For management of the telangiectasias, pulsed dye laser therapy has been used with variable response [5].

\section{Case}

A female neonate born at term by spontaneous vaginal delivery was noted to have what initially appeared to be a bruised left arm. There was no history of shoulder dystocia and the initial diagnosis was thought to be birth trauma secondary to the rapidity of her delivery, or potentially a haemangioma. Systemic examination found no other anomalies, with her weight and head circumference plotting on the $75^{\text {th }}$ centile on day 1 of life. She was moving her limbs appropriately and was neurologically intact with normal reflexes and tone. She was therefore discharged with a plan to review her in the outpatients department as the cutaneous lesions were felt to be benign.

The bruised discolouration of her left arm had improved somewhat when we reviewed her in the outpatients department at 25 days of age. However, we did note that there was a degree of serpiginous mottling that extended from the shoulder to the fingers of the left arm (Figure 1). This resembled cutis marmorata but was persistent, which excluded the diagnosis of common cutis marmorata. We therefore suspected CMTC and as she displayed no other dysmorphic features, we decided to monitor her. She was reviewed again at four months of age and the diagnosis of cutis marmorata telangiectasia congenita was made due to the persistence of the mottling, and with no clear viable alternate explanation. All systemic investigations also revealed no abnormalities, so this was deemed to be an isolated phenotypic variant. Since then, the CMTC has not changed in appearance up to the age of nine months, and the plan is to offer pulsed dye laser therapy for the areas of telangiectasia if they persist at three years of age.

\section{Discussion}

CMTC poses a diagnostic challenge for clinicians. As it is extremely rare, clinicians are either entirely unfamiliar with it or have an extremely low index for clinically suspecting it. Hence, it is often mistaken for other pathologies (Table 1). However, given time the diagnosis becomes clearer due to the persistence of the telangiectasias. At this point the patient should undergo diagnostic investigations (both radiological and ophthalmological) to determine whether it is as a feature of a wider syndrome (Table 2 ) or in isolation-which may be considered as a diagnosis of exclusion.

\section{The future for CMTC}

Both the epidemiology and pathophysiology of isolated CMTC remain poorly understood. This is primarily a consequence of its rarity and as it is benign is isolation. There are genetic explanations for its occurrence [7,8], yet more primary sequencing data is required from affected individuals to strengthen these hypotheses.

Isolated CMTC does usually regress in most individuals. In the subset that it persists, there is a treatment option ${ }^{5}$ with pulsed dye laser therapy. However, in patients where this is ineffective, other treatment modalities should be investigated in order to reduce the potential psychological burden caused by such a cosmetic anomaly. These may even come to light as we gradually learn more about the pathology causing isolated CMTC.
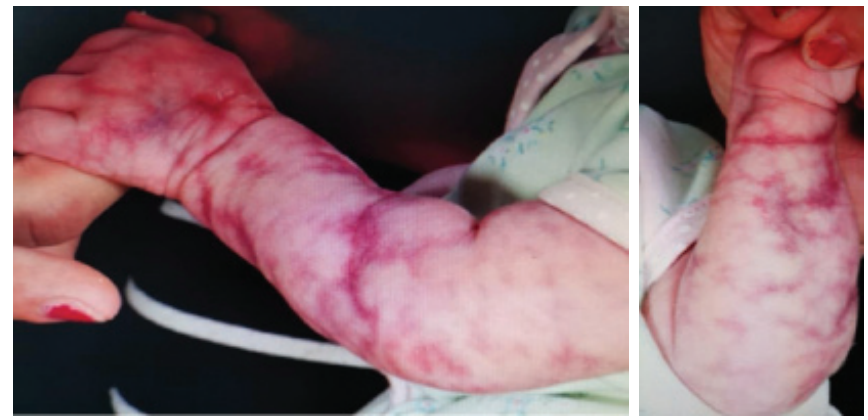

Figure 1: lateral and Ventral views of isolated CMTC of left arm.

Table 1: Phenotypic mimics for CMTC.

Bruising

Haemangioma

Port wine stain

Transient cutis marmorata

Neonatal lupus erythematous

Table 2: Syndromic associations of CMTC.

\begin{tabular}{|c|c|}
\hline Down's & Kartagener's \\
\hline Macrocephaly-Capillary Malformation & Klippel-Trenauney \\
\hline Adams-Oliver & Proteus \\
\hline De Lange & Homocytinuria \\
\hline Bocken-heimer & Divry-Van Bogaert \\
\hline
\end{tabular}

\section{References}

1. NORD Rare Diseases Database, Gerritsen MJP, Gerritsen R (2003) Cutis Marmorata Telangiectatica Congenita. In: NORD Guide to Rare Disorders. Philadelphia, PA: Lippincott Williams \& Wilkins 1000. Link: https://bit.ly/2UBuig1

2. Shareef S, Horowitz D (2020) Cutis Marmorata Telangiectasia Congenita. Stat Pearls. Link: https://bit.ly/2XbPiff

3. Jia D, Rajadurai VS, Chandran S (2018) Cutis Marmorata telangiectasia congenita with skin ulceration: a rare benign skin vascular malformation. BMJ Case Rept 2018. Link: https://bit.ly/2XOwRKi 
4. Van Lohuizen CHJ (1922) Cutis marmorata telangiectatica congenita. Acta Derm Venereol. (Stockh) 3: 202-211.

5. Elzouki AY, Harfi HA, Nazer H, Stapleton WOFB, Whitley RJ (2011) Textbook of Clinical Pediatrics 1558-1559.

6. Chen CP, Chen HC, Liu FF (1997) Cutis marmorata telangiectatica congenita associated with an elevated maternal serum human chorionic gonadotrophin level and transitory isolated fetal ascites. $\mathrm{Br} \mathrm{J}$ Dermatol 36: 267-271. Link: https://bit.ly/2JyOskv
7. Abumansour IS, Hijazi H, Alazmi A, Alzahrani F, Bashiri FA, et al. (2015) ARL6IP6, a susceptibility locus for ischemic stroke, is mutated in a patient with syndromic Cutis Marmorata Telangiectatica Congenita. Hum Genet 134: 815-822. Link: https://bit.ly/3dTpcDp

8. Happle R (1987) Lethal genes surviving by mosaicism: a possible explanation for sporadic birth defects involving the skin. J Am Acad Dermatol 16: 899-906. Link: https://bit.ly/2R7wY34

\section{Discover a bigger Impact and Visibility of your article publication with} Peertechz Publications

\section{Highlights}

* Signatory publisher of ORCID

* Signatory Publisher of DORA (San Francisco Declaration on Research Assessment)

* Articles archived in worlds' renowned service providers such as Portico, CNKI, AGRIS, TDNet, Base (Bielefeld University Library), CrossRef, Scilit, J-Gate etc.

* Journals indexed in ICMJE, SHERPA/ROMEO, Google Scholar etc.

- OAI-PMH (Open Archives Initiative Protocol for Metadata Harvesting)

* Dedicated Editorial Board for every journal

* Accurate and rapid peer-review process

* Increased citations of published articles through promotions

* Reduced timeline for article publication

Submit your articles and experience a new surge in publication services (https://www.peertechz.com/submission).

Peertechz journals wishes everlasting success in your every endeavours.

Copyright: @ 2020 Shakeel $\mathrm{H}$, et al. This is an open-access article distributed under the terms of the Creative Commons Attribution License, which permits unrestricted use distribution, and reproduction in any medium, provided the original author and source are credited. 